\title{
Lamellar Inclusions within Hyperplastic Endoplasmic Reticulum in Benign Mesothelial Cells
}

\author{
Simon Haefliger ${ }^{\mathrm{a}}$ Deepali Jain ${ }^{\mathrm{b}}$ Thomas Menter $^{\mathrm{a}}$ Tatjana Vlajnic $^{\mathrm{a}}$ \\ Spasenija Savic Prince ${ }^{a}$ Helmut Hopfer ${ }^{a}$ Michael J. Mihatsch ${ }^{a}$ \\ Lukas Bubendorf ${ }^{a}$ \\ aDepartment of Pathology, Institute of Pathology and Medical Genetics, University Hospital of Basel, \\ Basel, Switzerland; 'bepartment of Pathology, All India Institute of Medical Sciences, New Delhi, India
}

\section{Keywords}

Mesothelial cells · Inclusions · Endoplasmic reticulum .

Electron microscopy

\begin{abstract}
Introduction: In effusion cytology, mesothelial cells can occasionally present with striking intracytoplasmic accumulation of rod- and crystal-like cytoplasmic lamellar inclusions (LIs). Their nature and function are poorly understood, and their diagnostic relevance is unknown. Objective: The aim of this study was to explore the nature of LIs in mesothelial cells and determine their prevalence and diagnostic utility in routine practice. Material and Method: We reviewed a consecutive series of cytological specimens of reactive $(n=102)$ and malignant effusions ( $n=90$ ), respectively. Malignant effusions included malignant mesotheliomas $(n=63)$ and carcinomas $(n=27)$. Lls of one effusion were analyzed by electron microscopy (EM). Results: LIs were found exclusively in benign mesothelial cells in 14\% (14/102) of reactive and in 4\% $(1 / 27)$ of malignant effusions with carcinomatosis. They were absent in effusions of malignant mesothelioma. EM revealed mainly straight lamellar, less tubular, structures in cis-
\end{abstract}

karger@karger.com www.karger.com/acy

Karger $\stackrel{\text { ' }}{5}$

GOPEN ACCESS
(C) 2020 The Author(s)

Published by S. Karger AG, Basel

This is an Open Access article licensed under the Creative Commons Attribution-NonCommercial-4.0 International License (CC BY-NC) (http://www.karger.com/Services/OpenAccessLicense), applicable to the online version of the article only. Usage and distribution for commercial purposes requires written permission. ternae of the hyperplasic rough endoplasmic reticulum (rER). Conclusion: Cytoplasmic LIs located within hyperplastic rER can be found in up to $14 \%$ of effusions restricted to benign mesothelial cells. They can be used as an indirect morphological clue favoring the diagnosis of benign effusion and helping the cytologist to differentiate between reactive and malignant mesothelial cells in daily practice.

(C) 2020 The Author(s)

Published by S. Karger AG, Basel

\section{Introduction}

The mesothelium consists of a monolayer of specialized pavement-like cells that line the entire surface of the 3 serosal cavities (pleural, pericardial, and peritoneal), providing a nonadhesive and protective surface [1]. Besides this protecting role, they are also implicated in the transport of soluble substances and cells across serosal cavities, in antigen presentation and in tissue repair [1]

We have observed a number of benign effusions containing mesothelial cells with rod-shaped, crystal-like la- 
Fig. 1. a-d Conventional cytology (Pap stain and MGG stain) highlighting mesothelial cells filled up with LIs (yellow arrows) $(\times 630$, Pap $(\mathbf{a}) ; \times 630$, Pap $(\mathbf{b}) ; \times 630$, Pap (c); $\times 630$, MGG (d)). Pap, Papanicolaou; MGG, May-Grünwald-Giemsa; LIs, lamellar inclusions.
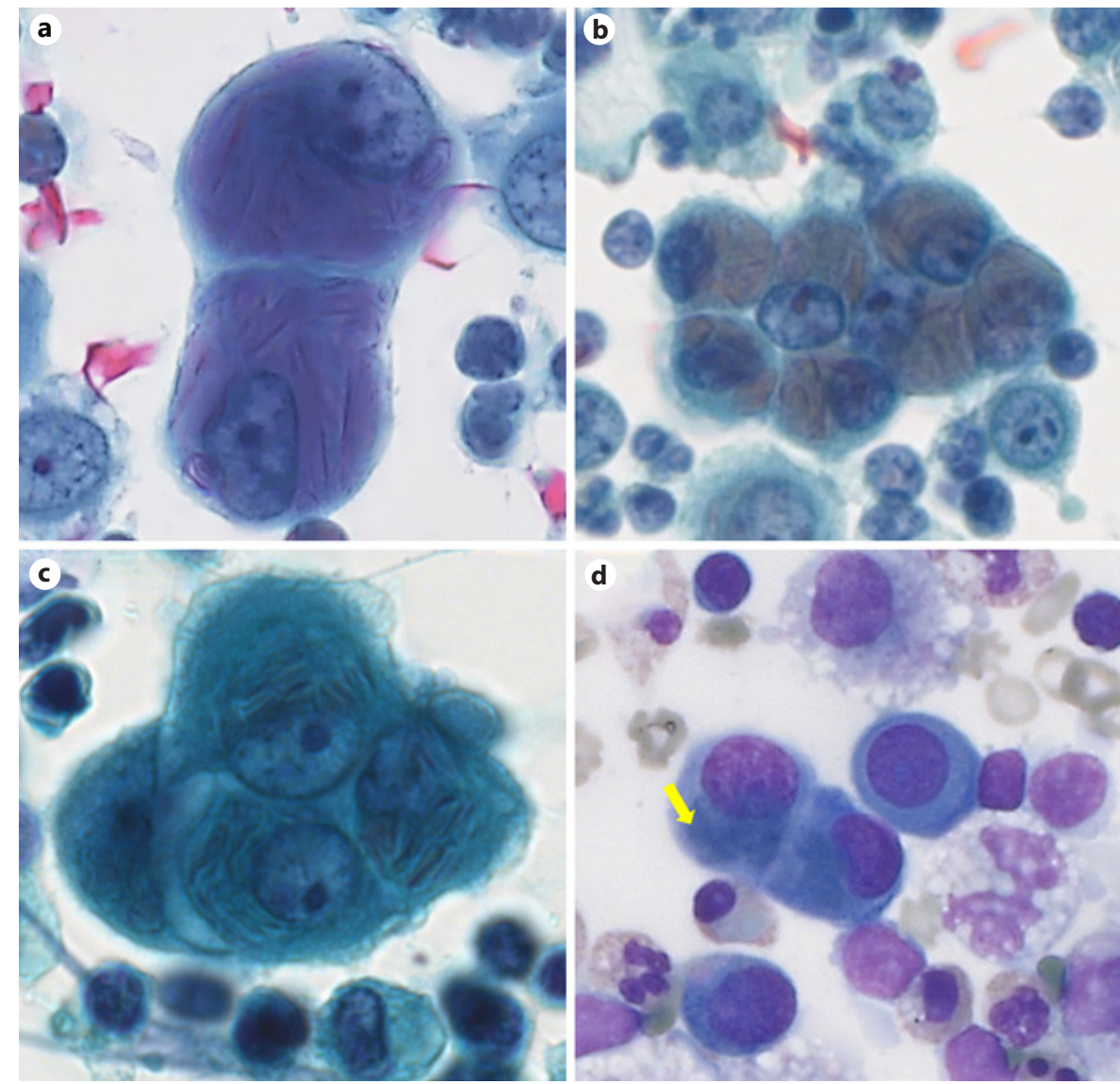

mellar inclusions (LIs). Such LIs have previously been described by Zaharopoulos et al. [2]. However, their nature and function in mesothelial cells remain poorly understood, and their prevalence and clinical implications are unknown. To determine their prevalence in benign and malignant effusions, we reviewed pleural and peritoneal effusion cytology findings of reactive and malignant effusions for the presence of LIs. Electron microscopy (EM) was applied to elucidate the nature of LIs.

\section{Material and Method}

\section{Review of Cases}

We reviewed a consecutive series of 102 Papanicolaou (Pap)stained benign pleural and peritoneal effusion specimens, diagnosed with reactive mesothelial cells and 27 cases with pleural or peritoneal carcinomatosis, diagnosed between 2017 and 2018. Further, we reviewed 63 Pap-stained cytological pleural specimens diagnosed with malignant mesothelioma between 2010 and 2018. All the samples reviewed were Pap-stained smear. For each case, one Pap-stained smear was screened for at least 1 min using a $\times 20 \mathrm{ob}-$ jective. Suspected LIs were confirmed at a magnification of $\times 63$.

\section{Transmission EM}

One index case with abundant LIs was further analyzed with transmission EM. For EM, the cells were fixed in $2 \%$ buffered glutaraldehyde at room temperature for $2.5 \mathrm{~h}$, then postfixed in $1 \%$ $\mathrm{OsO}_{4}$ for $1 \mathrm{~h}$ and embedded according to standard procedures in Spurr's epoxy resin. Ultrathin sections were stained with uranyl acetate and lead citrate and examined using a Zeiss 10C transmission electron microscope.

\section{Immunochemistry}

All the cells with LIs were characterized by immunochemistry using antibodies against calretinin (Clone Cal 6) and/or CD68 (Clone PG-M1) on previously Pap-stained specimens using the Leica Bond 3 automated immunostainer.

\section{Results}

Light Microscopic Definition of LIs in Mesothelial Cells LIs are defined as rod-shaped, crystal-like, non-birefringent structures distributed in a perinuclear distribution or occupying and expanding most of the cytoplasm (shown in Fig. 1a-d). LIs stained weakly reddish or purple 
Fig. 2. a, b Conventional cytology (Pap stain) with aggregate of mesothelial cells filled up with LIs ( $\times 630$, Pap). c, d Immunocytochemical stain showing diffuse cytoplasmic and nuclear positivity for calretinin and negativity for $\mathrm{CD} 68$ of the above depicted cells $(\times 630$, calretinin $(\mathbf{c})$; $\times 630$, CD68 (d)). Pap, Papanicolaou; LIs, lamellar inclusions.
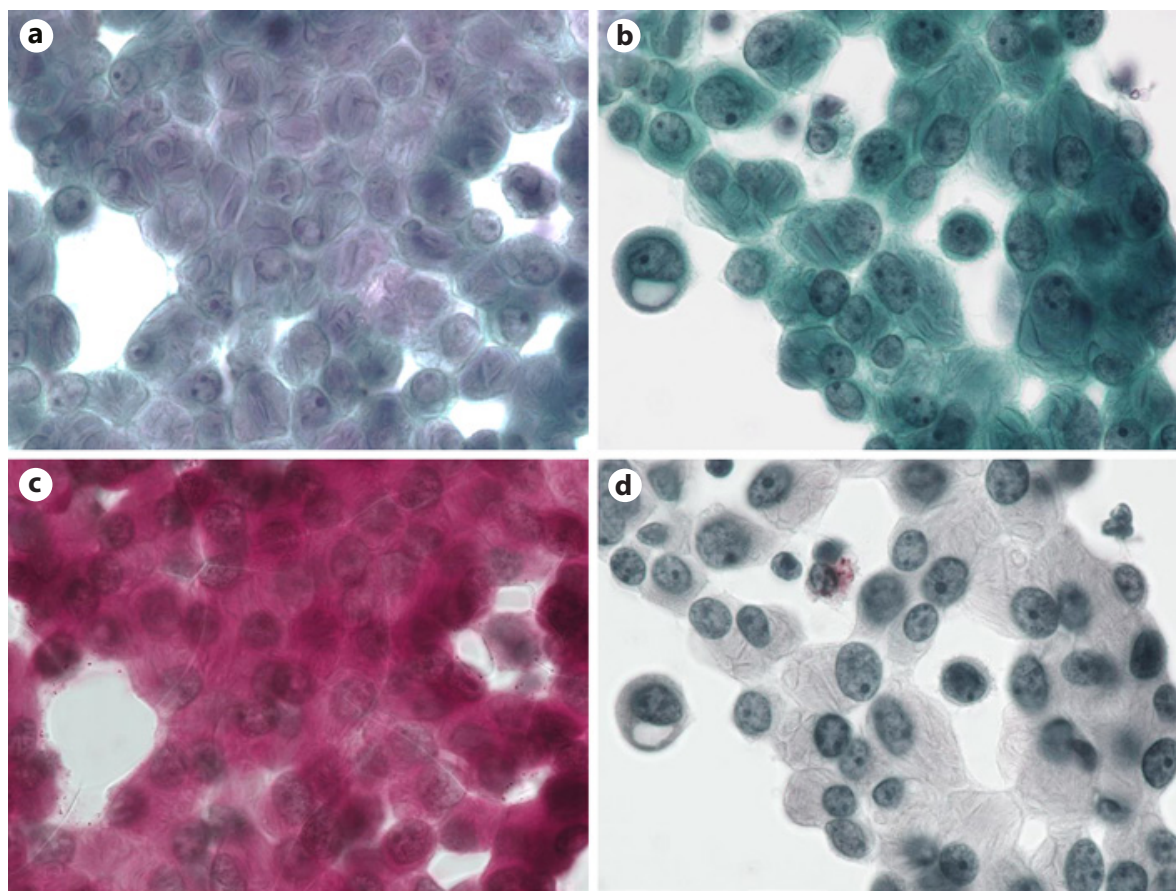

in the Pap-stained smears that had been fixed with Delaunay solution $(1,000 \mathrm{~mL}$ each of acetone and absolute alcohol and 20 drops of $1 \mathrm{~mol} / \mathrm{L}$ of trichloroacetic acid) (shown in Fig. 1a-c). Increasing the contrast by adjusting the aperture of the condenser enhances the typical rodshaped or crystal-like structure of LIs. Cases with prominent LIs were also detectable in air-dried May-GiemsaGrünwald specimens, where they appear as bluish perinuclear densities (shown in Fig. 1d). The mesothelial nature of the cells was confirmed by immunochemistry showing a diffuse positivity for calretinin and negativity for CD68 (shown in Fig. 2a-d).

\section{Electron Microscopy}

EM revealed that LIs were composed of mainly straight rarely curved bi- or multilayered lamellae or tubules in the cisternae of the hyperplastic rough endoplasmic reticulum (rER), as pictured and described by Ghadially [3]. These structures belong to the microtubule group of ordered arrays in the rER (shown in Fig. 3a-c). This interpretation was confirmed by several experts in EM analysis.

\section{Prevalence of LIs}

Benign mesothelial cells containing LIs were found in $13.7 \%(14 / 102)$ of all benign reactive effusions. LIs were more common in pleural effusions $(18 \% ; 13 / 72)$ than in peritoneal effusions $(3 \% ; 1 / 30)$. Benign mesothelial cells with LIs were found in only $4 \%(1 / 27)$ of cases with pleural carcinomatosis. In addition, no LIs were present in 63 effusions from malignant mesothelioma $(n=63)$. The number of LI-positive mesothelial cells in LI-positive effusions varied from very few to numerous but was always less than an estimated $30 \%$ of all mesothelial cells. LIs were restricted to mesothelial cells and were not found in macrophages.

\section{Discussion}

In this study, we describe cytoplasmic lamellar rodshaped, crystal-like inclusions which are present only in benign mesothelial cells. They are found in up to $18 \%$ of benign pleural and, less often, in peritoneal effusions. EM analysis shows that these LIs represent structures of hyperplastic rER. These structures belong to the microtubule group of ordered arrays in the rER.

LIs have previously been described by Zaharopoulos et al. [2] in 3 patients with benign effusions. They postulated that LIs were membranes of erythrocytes engulfed/ phagocytosed by mesothelial cells or macrophages [2]. In our study, LIs were only seen in mesothelial cells but not in macrophages, and no signs of erythrophagocytosis by mesothelial cells were found. Although it has been dem- 
Fig. 3. a Overview showing mesothelial cells with the cell in the upper part containing abundant LIs, which are distributed in a perinuclear fashion. Cells in the lower part without LIs (TEM, $\times 4,400$ ). b, c Higher magnification of the LIs of the cells shown before. The LIs consist of parallely arranged lamellae or tubules in the cisternae of the rER. Ribosomes connected to the rER as well as free ribosomes can also be appreciated. $\times 11,000$, TEM $($ b) $\times \times 71,000$, TEM (c). TEM, transmission electron microscopy; rER, rough endoplasmic reticulum; L, lysosome; LIs, lamellar inclusions; $\mathrm{N}$, nucleus; $\mathrm{M}$, mitochondria; $\mathrm{R}$, ribosomes; FR, free ribosomes; ER, endoplasmic reticulum.
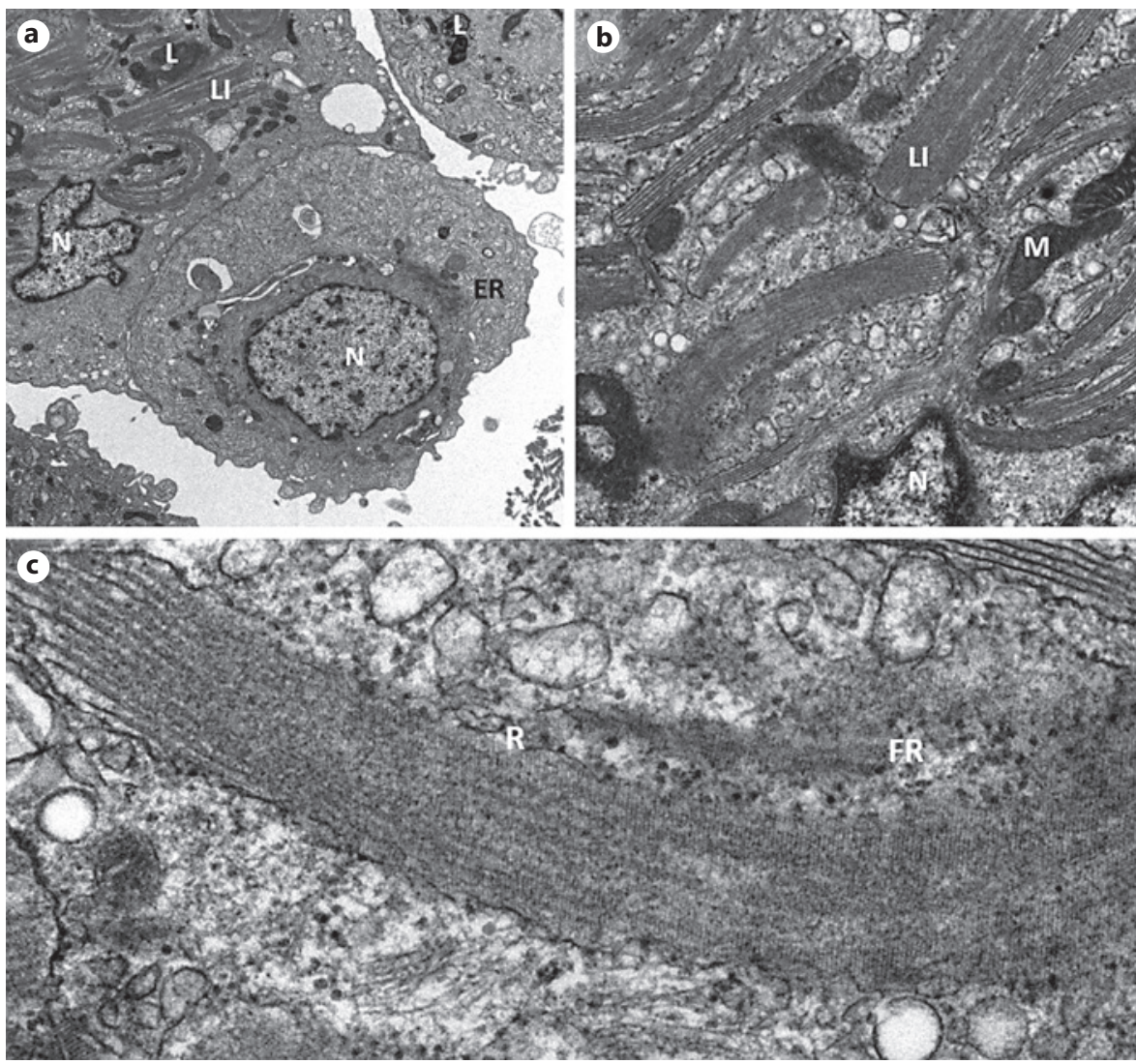

onstrated that human peritoneal mesothelial cells are capable of engulfing dying ovarian and colorectal cancer cells and, as such, mesothelial cells can, therefore, exhibit phagocytic capability, our EM studies clearly rule out the above hypothesis [4]. Normal mesothelial cells contain glycogen, microtubules and microfilaments, few mitochondria, a poorly developed Golgi apparatus, and very little ER [1]. Following injury or any stimulation of the serosal surfaces, an activation of the cells may occur with abundant cell organelles such as mitochondria, well-developed ER, and prominent Golgi apparatus [5, 6]. The cause of hyperplasia of rER in mesothelial cells remains unclear. ER is the largest organelle of eukaryotic cells and has numerous functions. For example, it plays a vital role in the synthesis of proteins, lipids, and glycogen; mediates the transport of proteins to other organelles and the cell membrane; and also serves as a $\mathrm{Ca}^{2+}$ storage site [7]. These functions suggest that rER hyperplasia might result from an increased metabolism and protein or lipid synthesis of the mesothelial cells in the context of reactive changes. Apparently, this reaction seems to be a physiological process of benign cells, as we did not observe it in mesothelioma cells. Clearly, further studies are needed to identify the underlying causes of hyperplasia of the rER in mesothelial cells. The cause of the difference in frequency noted between reactive pleural and peritoneal mesothelial cells in respect of LIs also remains unclear.

Differentiating reactive from malignant mesothelial cells can be challenging as malignant cells can sometimes be morphologically indistinguishable from benign, reactive mesothelial proliferations, or even from macrophages. In this study, we showed that although relatively rare, the presence of LIs in mesothelial cells could be used as an indirect morphological clue favoring benign changes and can, thus, help the cytologist in differentiating between reactive and malignant mesothelial or epithelial cells. However, it should be emphasized that the reason why this phenomenon occurs with varying frequency in tumor-free effusions is not clear. In summary, we have shown that LIs in mesothelial cells are part of hyperplastic rER and that their presence in mesothelial cells can be used as a simple, adjunct morphological sign of benignity in daily practice. 


\section{Acknowledgements}

We thank Claudia Lautenschlager for performing EM. We thank J. Schröder (Regensburg, Germany), B. Wagner (Sheffield, UK), and F. Gudat (Basel, Switzerland) for their help in the interpretation of the electron micrographs.

\section{Statement of Ethics}

This study was covered by the local institutional approval EK 253/08 on human research ("Ethikkomission beider Basel"). The subjects gave their written informed consent.

\section{Conflict of Interest Statement}

The authors have no conflict of interest to declare.

\section{Funding Sources}

The authors have no funding to declare.

\section{Author Contributions}

L.B. conceived and designed the project. J.D., S.H., T.M., H.H., M.J.M., and L.B. analyzed the data. S.H. and L.B. wrote the draft manuscript. T.V., M.J.M., and S.S. worked on the manuscript. All authors agreed to the content of the manuscript.

\section{References}

1 Mutsaers SE. The mesothelial cell. Int J Biochem Cell Biol. 2004 Jan;36(1):9-16.

2 Zaharopoulos P, Wen JW, Wong J. Membranous lamellar cytoplasmic inclusions in histiocytes and mesothelial cells of serous fluids. Their relationship to phagocytosis of red blood cells. Acta Cytol. 1998 Jun;42(3):607-13.

3 Ghadially FN. Ultrastructural pathology of the cell and matrix: a text and atlas of physiological and pathological alterations in the fine structure of cellular and extracellular components. 4th ed. Boston: ButterworthHeinemann; 1997. p. 514-9.
4 Wagner BJ, Lindau D, Ripper D, Stierhof YD, Glatzle J, Witte M, et al. Phagocytosis of dying tumor cells by human peritoneal mesothelial cells. J Cell Sci. 2011 May;124(Pt 10):1644-54.

5 Mutsaers SE. Mesothelial cells: their structure, function and role in serosal repair. Respirology. 2002 Sep;7(3):171-91.
6 Mutsaers SE, Whitaker D, Papadimitriou JM Stimulation of mesothelial cell proliferation by exudate macrophages enhances serosal wound healing in a Murine model. Am J Pathol. 2002 Feb;160(2):681-92.

7 Alberts B, Johnson A, Lewis J, Morgan D, Raff $\mathrm{M}$, Roberts $\mathrm{K}$, et al. Molecular biology of the cell. 6th ed. New York: Garland Science; 2002. p. 669-94. 